\title{
Thermoregulation of Barbados Black belly and West African type ewes and seasonal effects of climate on pre-weaning performance of lambs reared under a pasture based system in a tropical environment
}

\author{
Dean Avril ${ }^{1 \dagger}$, Cicero H. O. Lallo ${ }^{1}$, Kieshel Percy ${ }^{2}$, Gregory Bourne ${ }^{3}$, Paul Thomas ${ }^{2}$ and \\ Ruby Warner
}

'Open Tropical Forages-Animal Production Laboratory, Department of Food Production, Faculty of Science and Agriculture, The University of the West Indies, St. Augustine Campus, Republic of Trinidad and Tobago; ${ }^{2}$ Division of Agriculture, Marine Affairs and the Environment, Tobago House of Assembly, Republic of Trinidad and Tobago; ${ }^{3}$ School of Veterinary Medicine, Faculty of Medical Sciences, The University of the West Indies, Mount Hope, Republic of Trinidad and Tobago West Indies

Pasture based systems are considered to be more sustainable than those that depend on high imported concentrate feedstuff. However, it is a common practice in the Caribbean for animals to be kept at pasture without proper shade and water because the farmers believe that the animals are adapted. The thermoregulation of Barbados Blackbelly (BB) and West African (WA) type ewes and seasonal effects on pre-weaning performance of lambs from ewes managed at pasture at the Blenheim Sheep Multiplication and Research Project were studied. Rectal temperature (RT), respiration rate (RR), and infrared thermography were used to assess the thermoregulation of ewes. The temperatures and respirations per/min was taken at 8:00 in the morning before they go out to pasture and at 3:00 when they return. RT and RR data were subjected to repeated measure analysis. Both types showed no significant difference $(P>0.05)$ with regards to their thermoregulatory processes, with the exception of RT which was higher $(P<0.001)$ for WA in the afternoon. Rectal temperature for BB and WA was 38.34 and $38.41^{\circ} \mathrm{C}$ in the morning whereas it was 39.14 and $39.45^{\circ} \mathrm{C}$ in the afternoon, respectively. Barbados Blackbelly showed a 2.8 fold increase in RR when they returned from pasture compared to 3.0 fold increase for WA ewes. Heat was lost in the facial area and underbelly and between the legs in the morning and when they returned from pastures in the afternoon heat lost was observed throughout the entire body surface including facial areas. The lamb pre-weaning performance was analysed for the period of 1999 to 2004 . Birth weight, weaning weight and pre-weaning growth weight of lambs were analysed according to the GLM procedure. The fixed effect in the model included year of birth, season of birth, season of conception, birth type, sex and breed. Significant differences $(P<0.05)$ were observed between years, sex and birth type for the parameters birth weights, pre-weaning average daily gain and weaning weights. There were no significant differences $(P>0.05)$ between WA and BB for birth weights $(2.78 \mathrm{vs} .2 .71 \mathrm{~kg})$, weaning weights $(12.26 \mathrm{vs}$. $11.69 \mathrm{~kg})$ or preweaning growth rates $\left(124\right.$ vs. $\left.115 \mathrm{~g} \mathrm{~d}^{-1}\right)$, respectively. Season of conception significantly $(P<0.05)$ influenced birth weights but not preweaning average daily gain or weaning weights $(P<0.05)$. Season of birth effect was significant $(P<0.05)$ for birth weights and pre-wean average daily weight gain but not weaning weights $(P>0.05)$. Temperature humidity index (THI) was significantly $(P<0.05)$ higher in the wet compared to the dry season $79.60( \pm 0.13)$ vs $77.98( \pm 0.24)$, respectively. Litter size distribution by season indicated that there was only a $4.1 \%$ reduction in litter size in the dry season. In the current study birth weight of lambs conceived in the dry season was $2.5 \%$ lighter than lambs conceived in the wet season $(P<0.05)$ and lambs born in the dry season were heavier than those born in the wet season $(P<0.05)$. It is well known that heat stress in early and late gestation can cause a decrease in lamb birth weight. Single and twin lambs born in the dry season also had heavier birth weight than single lambs born in the wet season. However, there was no significant $(P>0.05)$ effect of season on conception or season of birth on weaning weight of lambs. It was concluded that although these types were well adapted to this tropical climatic region, better pasture management in terms of providing shade and water need to be implemented to improve thermotolerance of these ewes at pasture. The environmental impact of climate (dry vs wet) exerts an influence on preweaning performance of lambs produced from these ewes.

\footnotetext{
† E-mail: massalal01@gmail.com
} 